Article

\title{
Sustainable Urbanization Synergy Degree Measures-A Case Study in Henan Province, China
}

\author{
Leilei Jiao, Fumin Deng and Xuedong Liang * \\ The Economy and Enterprise Development Institute, Sichuan University, Chengdu 610065, China; \\ 2015225025013@stu.scu.edu.cn (L.J.); dengfm@scu.edu.cn (F.D.) \\ * Correspondence: liangxuedong@scu.edu.cn; Tel.: +86-028-8541-5581
}

Received: 11 November 2017; Accepted: 19 December 2017; Published: 21 December 2017

\begin{abstract}
Sustainable urbanization emphasizes properly handling the relationships between people, people and society, and people and nature in the process of urban development. However, sometimes these interactions are difficult to quantify. Through an analysis of the structure and functions of the sustainable urbanization system, this paper introduced synergetic theory and constructed a sustainable urbanization synergy system (SUSS) with five subsystems; demographic change, economic development, spatial structure, environmental quality, and social development; to study the synergistic development and orderly evolution trend of the sustainable urbanization composite system. Using sustainable urbanization in Henan province as an example, a mathematical quantitative model was established to measure the subsystem order degrees and the composite system synergy degree from 2006 to 2015. The results were consistent with the actual situation and indicated that over time, sustainable urbanization in Henan developed towards a more harmonious and orderly state, though the overall synergy degree was not high. It was found that the model was a sound basis for scientific judgment and effective decision-making when seeking to coordinate sustainable urbanization.
\end{abstract}

Keywords: sustainable urbanization; order degree; synergy degree; CRITIC method; Henan province

\section{Introduction}

Urbanization is an inevitable trend of social development that is booming rapidly in all parts of the world, especially in developing countries [1], and it has been identified as one of the most important development strategies in the twenty-first century [2]. Since the implementation of the "Reform and Opening-Up" policy in the late 1970s, China has been experiencing rapid urban development [3,4], which has led to an expansion in urban spaces, enlarged city scales, and lifestyle changes, and has enhanced economic development, improved people's living standards and resulted in many other visible benefits [5,6]. However, due to a lack of rational collaborative planning, the rapid and disordered economic development, industrialization and urbanization processes have resulted in various environmental and social problems-air and water pollution, resource depletion, reductions in biodiversity, chaotic and dysfunctional urban space, traffic congestion, disordered urban morphological structure, social conflicts, unbalanced development and land shortages $[7,8]$-all of which have restricted the healthy development, reduced the quality and affected the overall level of urbanization. To address these challenges, focus needs to be placed on improving the quality of urbanization and developing sustainable urbanization practices $[9,10]$.

Sustainable urbanization requires that urban development satisfy the ecological, economic, and societal needs in an urban space [11,12] and also considers the demands of future generations; that is, sustainable urbanization is focused on the coordinated development of the population, the economy, urban spaces, the environment, and the overall society under geographical conditions 
and development direction restrictions. In other words, sustainable urban development involves a rational distribution within the urban space, steady economic growth, ecological stability, reasonable population density, and improved social security. Therefore, to achieve these development goals, it is necessary to take an ecological, intensive, open, and synergetic sustainable urban development path [13].

The evaluation of urban development quality and the exploration of evolutionary trends of sustainable urbanization can be helpful in rational collaborative planning of urbanization [14]. To effectively measure the sustainable urbanization situation, and ensure the coordinated and orderly operation of a sustainable urbanization composite system, in this paper, synergetic theory and the CRITIC method are introduced to allow for the measurement of sustainable urbanization and ensure the sustainable urbanization composite system is coordinated and orderly. The main processes in this study are as follows. First, an order parameter system for the sustainable urbanization synergy system is developed based on previous research results, after which, a quantitative analysis model is established based on synergetic theory. The subsystem order degree and composite system synergy degree are then analyzed to study the degree of sustainable urbanization within the system.

\section{Literature Review}

\subsection{Research on Sustainable Urban Development}

Urbanization and the accompanying social developments have meant that the interrelationships and interactions between society and the environment have become increasingly complex. Many studies have focused on sustainable urban development with the aim of finding solutions to unfavorable urbanization planning so as to provide new urbanization paths, which can be summarized from three perspectives:

(1) Analyses of the changes brought about by urbanization. Srinivasan et al. [15] studied the relationship between urbanization and water resource vulnerability in a fast-growing city and found that some generalizable factors exist in the highly site-specific link between urbanization and water vulnerability, for which some feasible suggestions on water resource vulnerability were offered. Shen et al. [16] examined the link between urbanization and resource utilization and predicted that as there was going to be an increased demand for energy and mineral resources for China's continuing urbanization plans up till 2050, the government sector needed to review and improve existing resource utilization and environmental policies to ensure sustainable urban development. Li and Ma [17] established environmental quality indices for 30 administrative regions in China from 2003 to 2011, and employed panel data analyses to explore the relationships between the urbanization rate, economic development, and environmental change, with the results revealing an inverted-U-shaped relationship between the urbanization rate and regional environmental quality changes, and a "turning point" at around a $60 \%$ urbanization rate. Zhang et al. [18] studied the effects of industrial structure, infrastructure development, land use changes, and income on sustainable urban development, and found that with steady economic growth, moderate land use changes were the key to sustainable urban development. Dewan et al. [19] investigated the link between rapid urbanization growth and flood disasters in Bangladesh and concluded that urbanization had a significant influence on flood occurrences.

(2) Construction of sustainable urban development measurement indices. Measurement indices play an important role in information extraction and urbanization evaluations, however, due to different foci and research perspectives, different scholars have utilized different indices. Overall, in Refs. [20-22], there was a consensus that sustainable urbanization could be assessed from economic, social, environmental, and resource sustainability perspectives. Moreover, Jochen et al. [23] outlined thirteen suitability criteria for measuring urbanization expansion, providing a helpful and useful reference for the systematic assessment of the consistency and reliability of urban development metrics. To assess the urban sustainability of Chinese megacities, 
Huang et al. [24] listed eight indicators from the three dimensions of sustainability such as an environmental performance index, a human development index, and a Gini coefficient. Shen et al. [25] examined nine different practices using different indicators based on particular needs, and proposed a comparative analysis across four dimensions: environmental, economic, social, and government. Mori and Yamashita [26] selected environmental, economic, and social indices and established a framework of city sustainability indices to assess the performance of sustainable urbanization. All of these studies have provided valuable contributions to sustainable urbanization indicator systems from diverse perspectives.

(3) Sustainable urbanization measures. With the advancement of urbanization, the methods, techniques, and tools for assessing sustainable performance in the process of urbanization have made remarkable progress. Zhang [27] proposed a bi-dimensional matrix model for sustainable urbanization to analyze the performance of economic, social and environmental issues at different stages of new lifecycles of urban and rural environments, providing a reference for sustainable urbanization. Li et al. [28] analyzed panel data collected from 2000 to 2008 for Lianyungang and established a coupling coordination degree model to measure coordination between urbanization and the environment. Liang et al. [6] constructed a PCA-Grey-TOPSIS model to measure sustainable urban development capacities by combining principal component analysis with Grey TOPSIS. Thirteen cities in the Jiangsu province, China were selected as the study object to measure their sustainable development capacity, from which the model's effectiveness and operability were proven. Principal component analysis (PCA) [29] and the entropy method [30] were used to develop a sustainable urban development system evaluation model for assessing the performance of sustainable urbanization and a range of evaluation standards were outlined.

\subsection{Summary of Previous Research}

From the review and analyses of the existing sustainable urbanization research systems, several omissions were identified.

Based on previous studies of urban development, it is clear that previous research on urbanization has tended to primarily focus on one specific activity or one specific aspect of the economy, the society, or the ecology; therefore, the accompanying research dimensions or perspectives were relatively singular, and the overall synergistic effectiveness of integral urbanization was ignored. However, the essence of sustainable urbanization is the coordinated development of the whole system, with the core purpose being the promotion of harmony between the urban economy, the residents' lives, the natural resources, and the ecological resources through regional co-ordination, resource conservation, and other means [6]. Therefore, all aspects related to sustainable urbanization need to be collectively considered to ensure that the overall development situation is accurately reflected. Another issue in previous research is that there has been a tendency to employ qualitative analyses to assess sustainable urbanization performances, and to examine the links between urbanization, natural resources, and environmental impacts; therefore, as there has been a lack of quantitative research, the depth and accuracy of the research requires improvement. In addition, most scholars focus on the macro level, and there have been few studies on sustainable urbanization evolutionary trends or synergetic system mechanisms.

In view of the above, by introducing synergetic theory and the CRITIC method, this paper conducted a study of the synergetic degree of the urbanization process from the perspective of sustainable development, and established a sustainable urbanization synergy degree model. A case study in Henan province, China was presented, which can provide a scientific reference for guiding the coordinated development of the level and quality of urbanization in Henan. Accordingly, the innovations of this paper are presented from the following three aspects:

(1) On the basis of previous research, this paper developed a more comprehensive SUSS that included demographic change, economic development, space structure, environmental quality, and social 
development. For these five subsystems, more accurate order parameters were selected to allow for the analyses of the subsystems' evolutionary processes. Through the determination of the subsystem order degrees, the synergistic development level of the sustainable urbanization composite system can be more easily analyzed.

(2) Grounded by the principles associated with a comprehensive, integrated index system, a sustainable urbanization synergy degree measurement model was established. The CRITIC method was used to obtain the objective weights of each order parameter, and a quantitative analysis was then carried out using this model in order to reflect the coordination of sustainable urbanization and understand the urbanization development status and future tendencies.

(3) From the calculation of the order parameter weights, the subsystem order degrees and the composite system synergy degree, the coordinated development status and the orderly evolutionary trends of sustainable urbanization system in different years were analyzed from the perspective of time series.

\section{SUSS Analysis}

Synergetics was founded in 1976 by the German theoretical physicist Professor Hermann Haken, and its basic idea is that each subsystem in the living and nonliving open system will generate synergetic effects through nonlinear interactions under certain conditions, which makes the old structure develop into a new ordered structural system that has undergone fundamental changes in time, space, nature, and function. Sustainable urbanization is an open and nonlinear complex system that encompasses society, economy, environment and other aspects [11,12] and its development process is a self-organizing system. Healthy and orderly urban development requires each element within the system to coordinate with and compete with each other, which was the driving force for the overall evolution of the sustainable urbanization system. Through this drive, the system will gradually reach an orderly state and develop in a specific direction. Therefore, the complex evolution of SUSS can be well analyzed by synergistic theory.

In order to carry out this study, a SUSS is created first. There have been many studies on sustainable urbanization systems. Shen et al. [20] divided the sustainable urbanization system into four parts: economic, social, environmental and resources. Qiao and Fang [31] analyzed the urbanization process and pointed out that urbanization is made up of four courses, namely, economic urbanization, spatial urbanization, demographic urbanization and social urbanization. In Refs. [32,33], researches also claimed that there were four aspects to be considered when constructing urbanization evaluation indices: demographic, economic, social, and environmental. The above divisions based on social structures effectively revealed the governing laws in each urbanization subsystem and the functional relationships between the subsystems.

The SUSS evolves with the constant exchange of energy and matter with the external environment, and at the same time, the system's internal subsystems and factors interact with each other in a nonlinear way. This study focuses on the regional level to probe into the synergy issues of sustainable urbanization, so the factors considered are different from those considered by urban planning and development. To better reflect the evolutionary characteristics of a sustainable urbanization system and highlight the concept of sustainable development, based on theoretical and practical research and dynamic models, this paper argues that when studying sustainable urbanization there are five subsystems which need to be considered: the demographic subsystem, the economic subsystem, the social subsystem, the spatial subsystem, and the ecological subsystem. The above five core subsystems, through mutual restriction, coordination, and the interaction between these aspects, will produce the urbanization synergy effect, that is, " $1+1>2$ " [34], which can promote the rapid and healthy development of urbanization. If any subsystem is in a state of being too fast or too slow, the system will lose its synergism and gradually deviate from the equilibrium state, which is not conducive to the promotion of sustainable urbanization. Figure 1 shows the operation mechanism of the SUSS. 


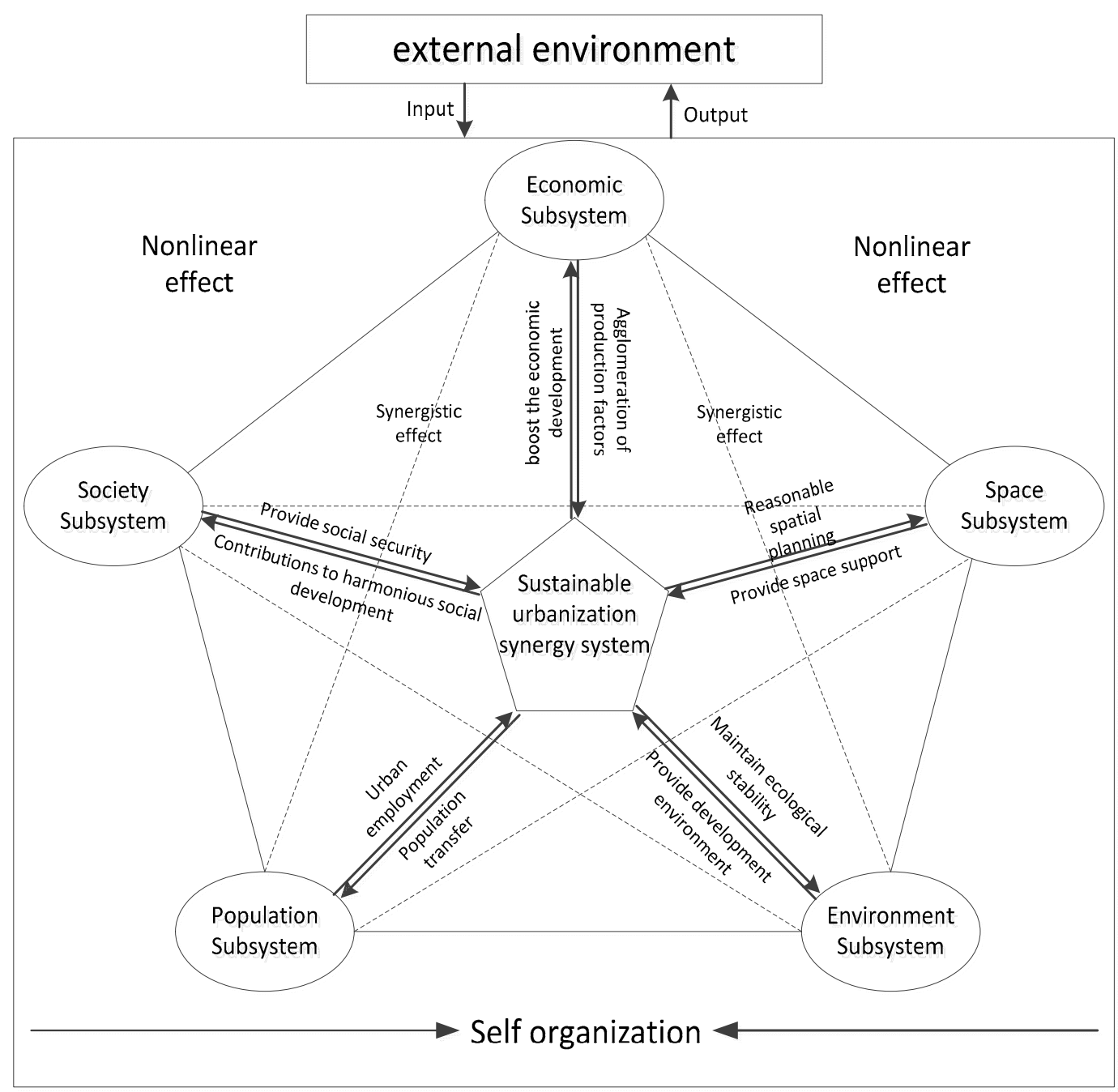

Figure 1. A sustainable urbanization synergy system (SUSS).

\section{The Order Parameter System of SUSS}

Urbanization from the perspective of sustainable development reflects the rational distribution of urban space, stable economic growth, ecological stability, reasonable population concentration and harmonious social development. The comprehensive synergy degree measurement for sustainable urbanization is essential not only to understand the complexity of the system but also to illustrate the synergistic evolution.

The construction of an effective synergistic measurement index system, therefore, is essential to accurately assess the synergy degree, which means that appropriate order parameters (indicators that reflect the evolutionary trends and urbanization characteristics) need to be identified and selected for each subsystem. According to synergy theory, variables that determine the system are called order parameters. The order parameter is generated by a single subsystem, which in turn dominates the behavior of each subsystem, reflecting the evolutionary trend of subsystems and composite system. From the analysis of the many factors affecting sustainable urbanization and following the principles of science, systematicness, operability, availability, and representativeness, a diagram of the relationships between influence factors of sustainable urbanization was constructed, as shown in Figure 2. 


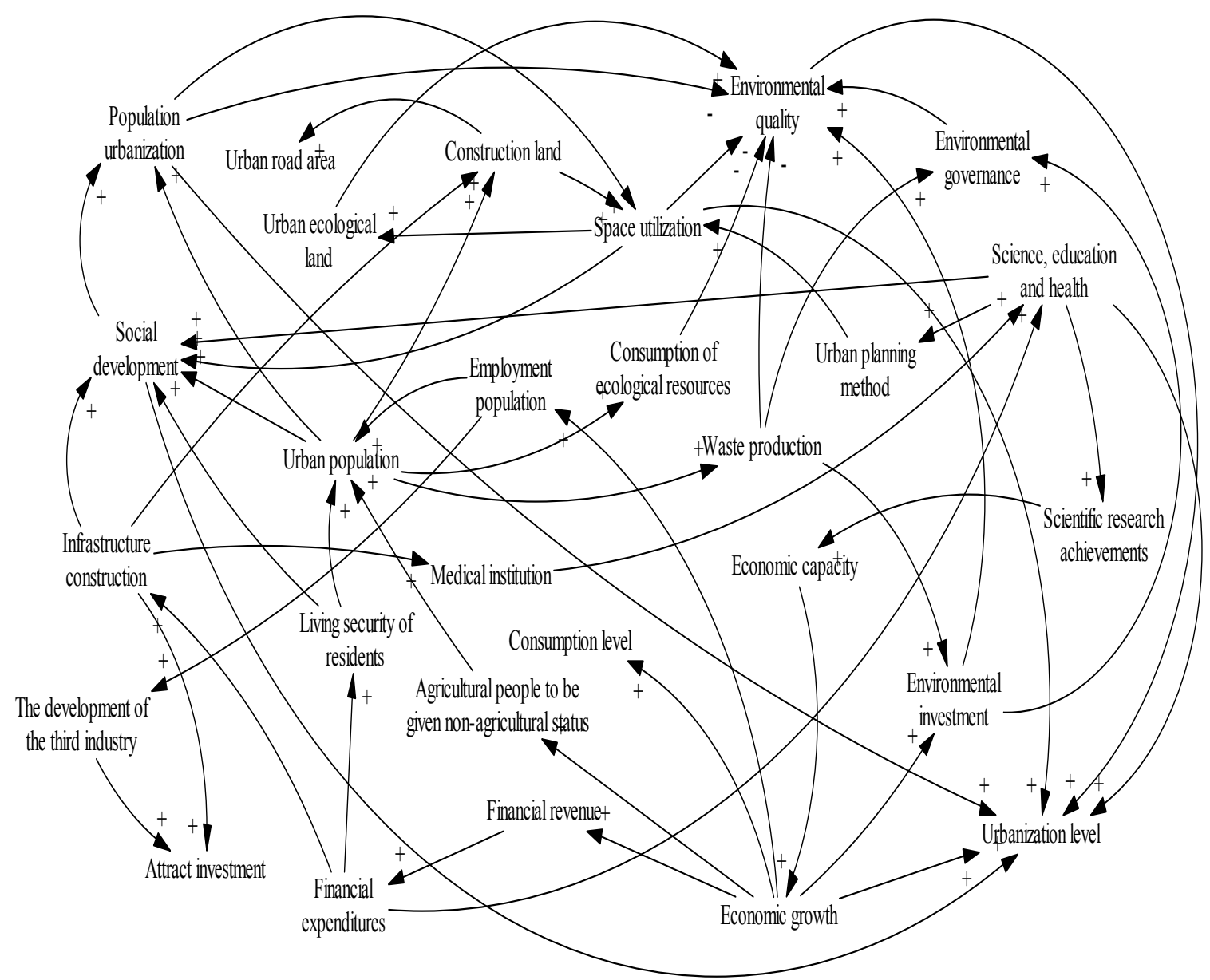

Figure 2. The relationships between influencing factors of sustainable urbanization.

Based on the inter-relationship analysis in Figure 2 and the "China Statistical Yearbook" and the "Henan Statistical Yearbook" over the years, the proper order parameters were selected and then a sustainable urbanization synergy degree measurement order parameter system was constructed. Table 1 shows the detailed order parameter system of the SUSS.

The SUSS consists of five subsystems, namely, demographic change, economic development, spatial arrangement, environmental quality, and social development, and each subsystem can be represented by one or more order parameters. The selection logic is as follows:

The demographic change subsystem reflects the changes in rural and urban populations. As urbanization results in high internal migration from rural areas to the cities and towns, there are upward changes in urban populations. Therefore, the urban population becomes the main factor by which to measure the scale of urbanization. Although the proportion of urban population has been the main indexes to evaluate the level of urbanization, as urbanization and urban scale expansions continue, the evaluation of population urbanization should not only be judged using this index. Therefore, to avoid the one sidedness of single index evaluations, the urban unemployment rate, the resident population in urban areas, the proportion of urban employed population in the total employed population, and the proportion of urban population to total population were selected as order parameters for the demographic change subsystem.

The economic development subsystem is the basic foundation and motivating force for urbanization. This subsystem mainly reflects the economic development strength, industrial structure optimization and industrial innovation ability which are closely related to the development of urbanization. When the economic level advances, with the convergence of occupation structure, 
income level, and education changes, rural residents' life satisfaction will increase. Based on this, we selected per capita GDP, the tertiary industry proportion, the disposable income of urban residents, comparison of consumption level between urban and rural residents, and the urban fixed asset investment accounted for GDP ratio as the order parameters of this part.

Table 1. Sustainable urbanization order parameter system.

\begin{tabular}{|c|c|c|c|}
\hline System & Subsystem & Order Parameters of Each Subsystem & Effect \\
\hline \multirow{23}{*}{$\begin{array}{l}\text { Sustainable urbanization } \\
\text { synergy system }\end{array}$} & \multirow{4}{*}{ Demographic change } & Urban unemployment rate $(\%) e_{11}$ & - \\
\hline & & Resident population in urban areas (million persons) $e_{12}$ & + \\
\hline & & $\begin{array}{l}\text { Proportion of urban employment to total employment } \\
\text { (\%) } e_{13}\end{array}$ & + \\
\hline & & Population urbanization rate $(\%) e_{14}$ & + \\
\hline & \multirow{5}{*}{ Economic development } & Per capita GDP (Yuan) $e_{21}$ & + \\
\hline & & Tertiary Industry Proportion (\%) $e_{22}$ & \pm \\
\hline & & Disposable income of urban residents (Yuan) $e_{23}$ & + \\
\hline & & $\begin{array}{l}\text { Comparison of consumption levels between urban and } \\
\text { rural residents (rural residents }=1 \text { ) } e_{24}\end{array}$ & - \\
\hline & & $\begin{array}{l}\text { Urban fixed asset investment accounted for GDP ratio } \\
\text { (hundred million yuan) } e_{25}\end{array}$ & + \\
\hline & \multirow{4}{*}{ Spatial structure } & The urban resident per capita road area (sq. m) $e_{31}$ & + \\
\hline & & Urban population density (persons/sq. km) $e_{32}$ & - \\
\hline & & Per capita living space of urban residents (sq. m) $e_{33}$ & + \\
\hline & & Built-up areas (sq.km) $e_{34}$ & + \\
\hline & \multirow{4}{*}{ Environmental quality } & Green coverage rate of built-up areas (\%) $e_{41}$ & + \\
\hline & & Harmless treatment rate of municipal solid waste $(\%) e_{42}$ & + \\
\hline & & Urban sewage treatment rate $(\%) e_{43}$ & + \\
\hline & & $\begin{array}{l}\text { Environmental governance investment (Hundred } \\
\text { million yuan) } e_{44}\end{array}$ & + \\
\hline & \multirow{6}{*}{ Social development } & Public transport standard operating vehicle numbers $e_{51}$ & + \\
\hline & & Total amount of patent authorization $e_{52}$ & + \\
\hline & & Gas popularization rate $(\%) e_{53}$ & + \\
\hline & & Medical insurance numbers in cities and towns $e_{54}$ & + \\
\hline & & $\begin{array}{l}\text { Internet connected computer numbers per } 100 \\
\text { households in cities and towns } e_{55}\end{array}$ & + \\
\hline & & $\begin{array}{l}\text { Bed numbers in hospital health centers at the end of the } \\
\text { year }\left(\times 10^{4}\right) e_{56}\end{array}$ & + \\
\hline
\end{tabular}

Note: "+" means that the index has a positive effect on the system, and "-" indicates that the index has a negative impact on the system; " \pm " means having a positive effect on the system at a reasonable value.

The spatial structure subsystem explains the urban spatial conditions and the residents' living conditions. Urban population aggregation accelerates the demand for construction land and the use of urban space; however, it cannot blindly expand. Sustainable urbanization needs a reasonable spatial layout that can effectively support the development of the social economy and ensure the stability of the ecosystem. Therefore, the order parameters selected were; the per capita living space of urban residents, built-up areas, the urban resident per capita road area to reflect urban resident housing levels, urban infrastructure construction, and the satisfaction degree of urbanization development. In addition, the density of the urban population reflects the characteristics of the city's spatial change and land structure [14] and indicates whether the population density in the city is crowded or not and whether the layout of space is reasonable or not. Only a moderate population density can guarantee the space for survival and life.

The environmental quality and social development subsystems are able to measure the urbanization development harmony and friendliness degree by considering how ecological governance and social mechanisms influence various aspects of the residents' lives. The green coverage rate of built-up areas can reflect whether the green space degree of urban is narrowing, the harmless 
treatment rate of municipal solid waste and the urban sewage treatment rate both reflect the greening level of urban ecological environments and imply an environmental cost for economic development. The environmental governance investment explains the level of government investment required to maintain a sustainable industrial environment. Social development order parameters, such as transportation, gas supply, social security indicators are available, and measure the level of social development. Public transport standard operating vehicle numbers reflect the level of urban public facilities, the total amount of patent authorization can give expression to the level of scientific and technological innovation, the gas popularization rate indicates the take up of clean energy, the medical insurance numbers in cities and towns reflect social security popularization levels, the number of Internet-connected computers per 100 households in cities and towns reflects the informatization level of urban residents, and the bed numbers in hospital health centers at the end of the year indicates the level of urban public health.

These five subsystems affect and interact with each other, and their interaction influences the evolution of the entire urbanization system. The coordinated development of the five subsystems will help to keep the entire system in an ordered and stable state, so as to promote urbanization development efficiency and boost the sustainable development of the city.

\section{Sustainable Urbanization Synergy Degree Measurement Method}

The synergy theory is a useful tool for systems science studies as it can reveal the common principle of the change in the updating process of the system development [35]. Since it was put forward by Hermann Haken in 1976, it has been applied in many fields such as logistics systems [36] and tourism planning [37]. In this paper, the synergy theory is introduced into the study of sustainable urbanization composite system. Synergy degree is used to measure the degree of coordination and collaboration between the subsystems within sustainable urbanization system, which can be reflected by order degrees of order parameters in each subsystem.

\subsection{Subsystem Order Degree Measurement Model}

Suppose a sustainable urbanization compound system consists of $i$ subsystems, $S=\left(S_{1}, S_{2}, \cdots, S_{i}\right)$, $i \in[1, k]$ and $k \geq 2$. In this research, $k=5$, which indicates that the sustainable urbanization system $(S)$ has five subsystems; a demographic change subsystem $\left(S_{1}\right)$, an economic development subsystem $\left(S_{2}\right)$, a spatial structure subsystem $\left(S_{3}\right)$, an environmental quality subsystem $\left(S_{4}\right)$, and a social development subsystem $\left(S_{5}\right)$.

The order parameters for subsystem $S_{i}$ are defined as $e_{i}=\left(e_{i 1}, e_{i 2}, \cdots, e_{i n}\right), n \geq 1, \beta_{i j} \leq e_{i j} \leq$ $\alpha_{i j}, j \in[1, n]$, with $\alpha_{i j}$ and $\beta_{i j}$ being the upper and lower limits of $e_{i j}$ at the critical system stability point. Generally, there are two kinds of order parameters; (1) the greater the value of the order parameter, the higher the subsystem order degree; and (2) the smaller the value of the order parameter, the higher the subsystem order degree. In this case, we suppose $e_{i 1}, e_{i 2}, \cdots, e_{i m}$ are the first kinds of order parameters and $e_{i m}, e_{i m+1}, \cdots, e_{i n}$ are the second kinds of order parameters. Therefore, the order degree for the sustainable urbanization subsystem can be expressed as:

$$
u_{i}\left(e_{i j}\right)=\left\{\begin{array}{c}
\frac{e_{i j}-\beta_{i j}}{\alpha_{i j}-\beta_{i j}}, j \in[1, m], e_{i j} \text { is positive index } \\
\frac{\alpha_{i j}-e_{i j}}{\alpha_{i j}-\beta_{i j}}, j \in[m+1, n], e_{i j} \text { is negetive index }
\end{array}\right.
$$

From Equation (1), it can be known that the order degree of the order parameter of subsystem $u_{i}\left(e_{i j}\right) \in[0,1]$, and the larger $u_{i}\left(e_{i j}\right)$ is, the more order parameter $e_{i j}$ contributes to the order degree of the subsystem. In addition, the total contribution of each order parameter to the subsystem is not only related to the numerical value of the order, but also related to their specific combination form; that is, the weight of each order parameter. In practice, the geometric mean method or linear weighted 
summation method is often used. In this paper, the linear weighting method is used to integrate the order degree of subsystem, namely:

$$
\begin{gathered}
u_{i}\left(e_{i}\right)=\sum_{j=1}^{n} \omega_{j} u_{i}\left(e_{i j}\right) \\
0 \leq \omega_{j} \leq 1, \sum_{j=1}^{n} \omega_{j}=1 .
\end{gathered}
$$

We know from Equation (2) that $u_{i}\left(e_{i}\right) \in[0,1]$ and the higher the $u_{i}\left(e_{i}\right)$ value is, the higher the order degree of subsystem $S_{i}$. Among them, the weight coefficient $\omega_{j}$ indicates the position of the order parameter $e_{i j}$ in the orderly operation of the subsystem, which can be calculated by the CRITIC method.

The CRITIC method is an objective weighting method that not only accounts for the influence of contrast strength size on the weights, but also accounts the conflict between the indices, which can effectively determine the index weight by using the product of the internal contrast strength of evaluation indices and the conflict between the indices [38,39]. According to the definition of the CRITIC method, $c$ is the information quantity of the order parameter in the evaluation system. Thus, the amount of information for the $j$-th order parameter is:

$$
c_{j}=\sigma_{j} \sum_{k=1}^{n}\left(1-r_{k j}\right), j=1,2, \cdots, n
$$

where $\sigma_{j}$ is the standard deviation of the $j$-th order parameter, and it can be used as a measure of contrast intensity; $r_{k j}$ is the correlation coefficient between the evaluation order parameter $k$ and the evaluation order parameter $j$; and $\sum_{k=1}^{n}\left(1-r_{k j}\right)$ represents the conflict between the order parameters.

The larger the value of $c_{j}$, the greater the information it contains and the greater the corresponding weight; therefore, the objective weight $\omega_{j}$ for the $\mathrm{j}$-th order parameters is:

$$
\omega_{j}=\frac{c_{j}}{\sum_{k=1}^{n} c_{j}}, j=1,2 \cdots, n
$$

\subsection{Sustainable Urbanization System Synergy Degree Measurement Model}

It is assumed that, at a given initial time $t_{0}$, the order degrees of the five subsystems of the sustainable urbanization system are $u_{1}^{0}\left(e_{1}\right), u_{2}^{0}\left(e_{2}\right), u_{3}^{0}\left(e_{3}\right), u_{4}^{0}\left(e_{4}\right), u_{5}{ }^{0}\left(e_{5}\right)$ and as the urbanization system dynamically evolves, the order degree of the five subsystems change to $u_{1}{ }^{m}\left(e_{1}\right), u_{2}{ }^{m}\left(e_{2}\right), u_{3}{ }^{m}\left(e_{3}\right), u_{4}{ }^{m}\left(e_{4}\right), u_{5}{ }^{m}\left(e_{5}\right)$ at time $t_{m}$. Then, the measurement model of urbanization synergy degree can be defined as follows:

$$
\mathrm{SD}=\theta\left\{\left|\prod_{i=1}^{k}\left[u_{i}^{m}\left(e_{i}\right)-u_{i}^{0}\left(e_{i}\right)\right]\right|\right\}^{1 / k}
$$

In Equation (5), $\theta$ should meet the following conditions:

$$
\theta=\frac{\min _{i}\left(u_{i}^{m}\left(e_{i}\right)-u_{i}^{0}\left(e_{i}\right) \neq 0\right)}{\left|\min _{i}\left(u_{i}^{m}\left(e_{i}\right)-u_{i}^{0}\left(e_{i}\right) \neq 0\right)\right|}, i=\{1,2,3,4,5\} .
$$

From Equation (6), when the order degree of the five subsystems all increases from time $t_{0}$ to $t_{m}$, $\theta=1$, otherwise, $\theta=-1$. Therefore, the range of the synergy degree value is $\mathrm{SD} \in[-1,1]$. The larger $\mathrm{SD}$ is, the higher the synergy degree of the urbanization system will be; on the contrary, the smaller SD is, the lower the synergy degree of urbanization system will be. Further, we can know from Equation (6) 
that only when $u_{1}{ }^{m}\left(e_{i}\right)-u_{1}^{0}\left(e_{i}\right)>0$, where $i=\{1,2,3,4,5\}$, can the synergy degree of urbanization system be positive, which means the whole urbanization system is developing in an orderly way from time $t_{0}$ to $t_{m}$. If the synergy degree value is negative in that period, it indicates the inharmonious development of the entire urbanization development system.

\subsection{Measurement Steps}

To sum up, the model of sustainable urbanization system synergy degree measurement is shown in Figure 3. The detailed calculation steps are as follows:

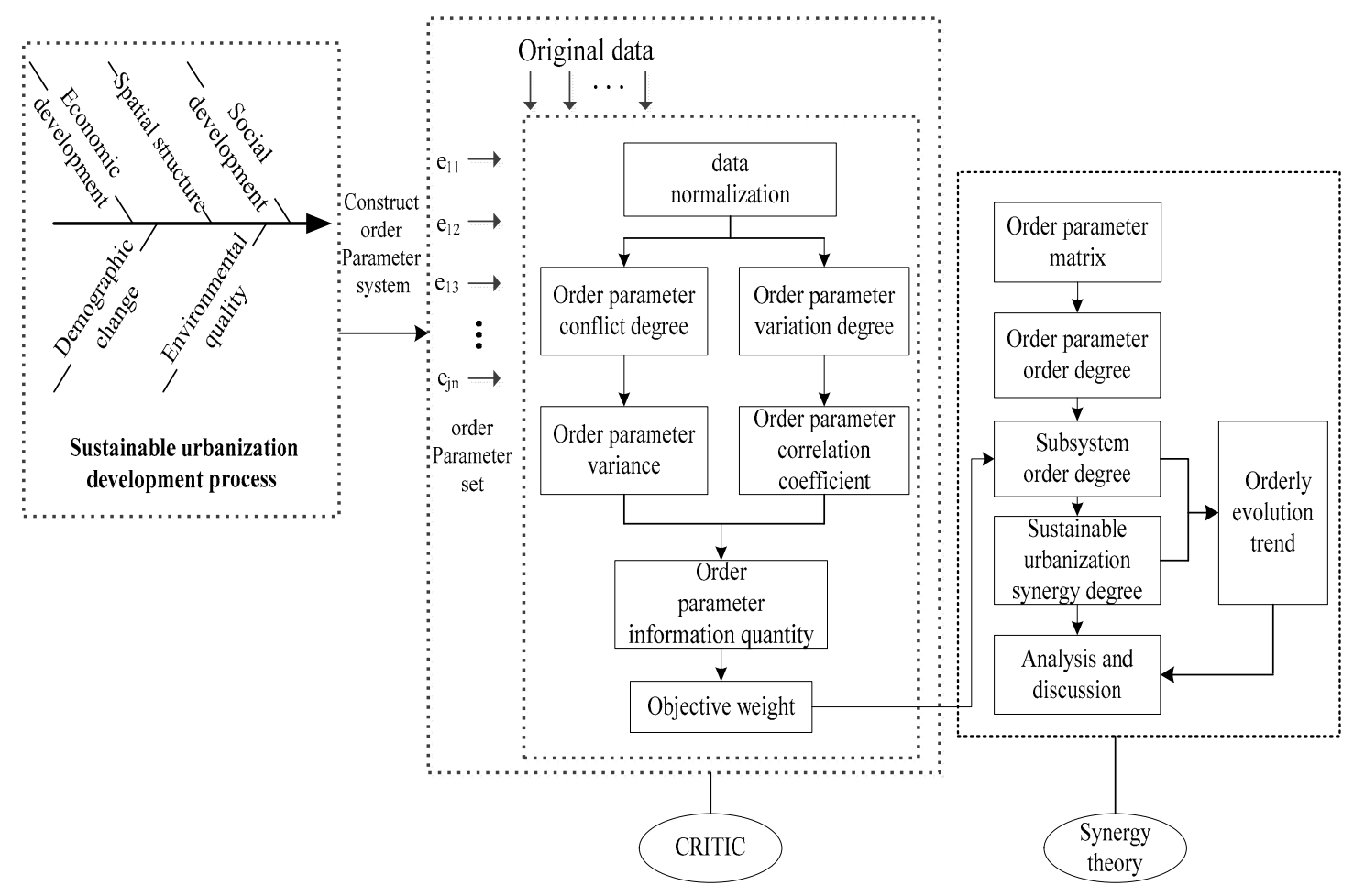

Figure 3. Sustainable urbanization synergy degree measurement model.

Step 1: Normalize original data. In order to eliminate the influence of the dimension of the original data on the measurement results, we firstly need to normalize the data. The normalization process is as follows:

$$
Z_{s j}^{\prime}=\frac{Z_{\mathrm{sj}}-Z_{\min }}{Z_{\max }-Z_{\min }}, s=1,2 \ldots m ; j=1,2 \ldots n
$$

where $Z_{s j}^{\prime}$ represents the normalized data, $Z_{\mathrm{sj}}$ is the raw data value for variable $s, Z_{\max }$ stands for the maximum order parameter value for subsystem $j$, and $Z_{\min }$ is the minimum order parameter value for subsystem $j$.

Step 2: Determine the correlation coefficient for each order parameter in the urbanization subsystem, and establish the correlation a coefficient matrix $R=\left[r_{k j}\right]_{n \times n^{\prime}}$

$$
r_{k j}=\frac{\operatorname{Cov}(k, j)}{\sqrt{\operatorname{Var}(k) \operatorname{Var}(j)}}
$$

where $\operatorname{Cov}(k, j)$ is the covariance of $k$ and $j . \operatorname{Var}(k)$ is the variance of $k$ and $\operatorname{Var}(j)$ is the variance of $j$. Then calculate the objective weight of them based on Equations (3) and (4). 
Step 3: Calculate the order degree values for the urbanization subsystem order parameters $u_{i}\left(e_{i j}\right)$ according to Equation (1). On this basis, the order degree of subsystems is obtained by the aggregation of Equation (2).

Step 4: Determine the sustainable urbanization synergy degree values using Equation (5).

\section{Case Analysis}

In this section, the Henan province of China is chosen as the study object to analyze the development and evolution in its sustainable urbanization. Henan is a large agricultural province in the central part of China, and has the highest population of all provinces in China. However, urbanization has been slow, with the quality being lower than the national average primarily because of slow and low quality urbanization and unbalanced development [40]. The characteristics of industrial structure in Henan province are as follows: (1) the proportion of agricultural output value is higher than that of other provinces; (2) industry is dominated by traditional industries and basic industries, and the level of development of tertiary industry is low; and (3) the size of the economy is larger. With such a background, the characteristics and causes revealed by an in-depth study of Henan urbanization mean that corresponding measures are very necessary and urgent to speed up the process of urban development.

According to the established order parameter system above, we chose Henan province, in China, as our research object. The original data of this study are derived from the "China Statistical Yearbook" (2007-2016) [41], the "Henan Statistical Yearbook" (2007-2016) [42], and some of the order parameter data were converted from the original data by calculation formulas. The Henan sustainable urbanization order parameter data is shown in Table 2.

The correlation coefficient matrix and the order parameter standard deviation were calculated by using SPSS software to find order parameters information quantity and weights for the sustainable urbanization system, the calculation results for which are shown in Table 3.

The order parameter order degrees, the subsystem order degrees, and the sustainable urbanization synergy degree were determined based on Equations (1), (2), and (5), as shown in Tables 4 and 5. 
Table 2. Order parameters raw data.

\begin{tabular}{|c|c|c|c|c|c|c|c|c|c|c|c|c|c|c|c|c|c|c|c|c|c|c|c|}
\hline \multirow{2}{*}{ Year } & \multicolumn{4}{|c|}{ Demographic Change } & \multicolumn{5}{|c|}{ Economic Development } & \multicolumn{4}{|c|}{ Spatial Structure } & \multicolumn{4}{|c|}{ Environmental Quality } & \multicolumn{6}{|c|}{ Social Development } \\
\hline & e11 & e12 & e13 & e14 & e21 & e22 & e23 & e24 & e25 & e31 & e32 & e33 & e34 & e41 & e42 & e43 & e44 & e51 & e52 & e53 & e54 & e55 & e56 \\
\hline 2006 & 3.5 & 3050 & 16.47 & 33 & 1 & 31 & 9810.26 & 3.4 & 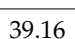 & 10 & 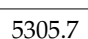 & 31.75 & 16 & 32.8 & 46.3 & 2 & 95.15 & 12,575 & 242 & 2.2 & 704 & 1.24 & 2.21 \\
\hline 2007 & 3.4 & & 16 & 34 . & 16,012 & 31.3 & & 3. & 2 & 10.81 & & & & & & & & 13,071 & 998 & 68.9 & 726.03 & 1.96 & 2.43 \\
\hline 2008 & 3.4 & . & 16.72 & 36.03 & 19,181 & 29.7 & & & 2 & 9.9 & 5967 & 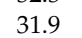 & $185 ?$ & 4 & 3 & 77.53 & 109.88 & 15,661 & 9133 & 66.9 & 840.87 & 0.88 & 2.71 \\
\hline 2009 & 3.5 & 3 & & & 20,597 & 31 & & 3. & 58 & 10.44 & & 32 & 191 & & 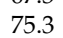 & 83.86 & 21.32 & 18,381 & 11,425 & 72.9 & 1970.13 & 35.21 & 3.15 \\
\hline 2010 & 3.4 & 3651 & 18.18 & 38.5 & 24,446 & 30.6 & $15,930.26$ & 5. & 60.34 & 0.25 & 517 & 33 & 201 & 36.5 & 82.5 & 87.58 & 132.25 & 18,912 & 16,539 & 73.4 & 2043.75 & 41.23 & 3.18 \\
\hline 2011 & 3.4 & & & 40.57 & & & & 3.2 & 62.88 & 10.83 & & & & & 84.4 & & & 20,860 & 19,259 & 76.2 & & 56.83 & 3.29 \\
\hline 2012 & 3.1 & 3991 & 21.99 & 42.43 & 31,499 & 33.8 & $20,422.62$ & 3 & 69.46 & 11.08 & 4964 & 34.7 & 2219 & 36.9 & 86.4 & 87.82 & 178.21 & 21,852 & 26,833 & 77.9 & 2222.2 & 59.38 & 3.52 \\
\hline 2013 & 3.1 & 4123 & 24.03 & 43.8 & 34 & 35.7 & & 2.9 & 78.25 & 11.57 & 4982 & 34.4 & 2289 & 37.6 & 90 & 90.88 & 288.1 & 22,790 & 29,482 & 82 & 2297.2 & 66.66 & 3.66 \\
\hline 2014 & 3.0 & 4265 & 27.27 & 45.2 & 37,0 & 37.1 & 23 & 2.7 & 85. & 11.67 & 51 & 38.18 & 23 & 38.3 & 92.8 & 92.51 & 317 & 25,257 & 33,366 & 83.8 & 2340.03 & 62.25 & 3.8 \\
\hline 2015 & 3.0 & 4441 & 27.71 & 46.85 & 39,123 & 40.2 & $25,575.6$ & 2.6 & 94.46 & 12.06 & 5155 & 38.35 & 2503 & 37.7 & 96 & 93.58 & 360.16 & 27,355 & 47,766 & 86 & 2344.9 & 60.61 & 3.73 \\
\hline
\end{tabular}

Table 3. Order parameters information quantity and weights.

\begin{tabular}{|c|c|c|c|}
\hline Subsystem & Order Parameters of Each Subsystem & Information Quantity & Order Parameters Weights \\
\hline \multirow{4}{*}{ Demographic change } & Urban unemployment rate $(\%) e_{11}$ & 0.1112 & 0.421 \\
\hline & Resident population in urban areas (million persons) $e_{12}$ & 0.0503 & 0.191 \\
\hline & Proportion of urban employment to total employment $(\%) e_{13}$ & 0.0576 & 0.218 \\
\hline & Population urbanization rate $(\%) e_{14}$ & 0.0450 & 0.170 \\
\hline \multirow{5}{*}{ Economic development } & Per capita GDP (Yuan) $e_{21}$ & 0.0772 & 0.197 \\
\hline & Tertiary Industry Proportion $(\%) e_{22}$ & 0.1106 & 0.283 \\
\hline & Disposable income of urban residents $e_{23}$ & 0.0592 & 0.152 \\
\hline & $\begin{array}{l}\text { Comparison of consumption level between urban and rural residents } \\
\text { (rural residents }=1) e_{24}\end{array}$ & 0.0844 & 0.216 \\
\hline & $\begin{array}{l}\text { Urban fixed asset investment accounted for GDP ratio (Hundred } \\
\text { million yuan) } e_{25}\end{array}$ & 0.0595 & 0.152 \\
\hline \multirow{4}{*}{ Spatial structure } & The per capita road area of urban residents (sq.m) $e_{31}$ & 0.2739 & 0.206 \\
\hline & Density of urban population (persons/sq.km) $e_{32}$ & 0.5686 & 0.428 \\
\hline & Per capita living space of urban residents (sq.m) $e_{33}$ & 0.2731 & 0.205 \\
\hline & Built-up area (sq.km) $e_{34}$ & 0.2143 & 0.161 \\
\hline
\end{tabular}


Table 3. Cont.

\begin{tabular}{|c|c|c|c|}
\hline Subsystem & Order Parameters of Each Subsystem & Information Quantity & Order Parameters Weights \\
\hline \multirow{4}{*}{ Environmental quality } & Green coverage rate of built-up area $(\%) e_{41}$ & 0.0818 & 0.154 \\
\hline & Harmless treatment rate of municipal solid waste $(\%) e_{42}$ & 0.0920 & 0.173 \\
\hline & Urban sewage treatment rate $(\%) e_{43}$ & 0.0920 & 0.173 \\
\hline & environmental governance investment (hundred million yuan) $e_{44}$ & 0.2652 & 0.500 \\
\hline \multirow{6}{*}{ Social development } & Public transport standard operating vehicle numbers $e_{51}$ & 0.0893 & 0.098 \\
\hline & Total amount of patent authorization $e_{52}$ & 0.1751 & 0.194 \\
\hline & Gas popularization rate $(\%) e_{53}$ & 0.1209 & 0.134 \\
\hline & Medical insurance numbers in cities and towns $e_{54}$ & 0.2455 & 0.272 \\
\hline & $\begin{array}{l}\text { Internet computer numbers per } 100 \text { households in cities and } \\
\text { towns } e_{55}\end{array}$ & 0.1632 & 0.181 \\
\hline & $\begin{array}{l}\text { Bed numbers in hospital health centers at the end of the year } \\
\left(\times 10^{4}\right) e_{56}\end{array}$ & 0.1088 & 0.121 \\
\hline
\end{tabular}

Table 4. Order degree of the order parameters of each subsystem.

\begin{tabular}{|c|c|c|c|c|c|c|c|c|c|c|c|c|c|c|c|c|c|c|c|c|c|c|c|}
\hline \multirow{2}{*}{ Year } & \multicolumn{4}{|c|}{ Demographic Change } & \multicolumn{5}{|c|}{ Economic Development } & \multicolumn{4}{|c|}{ Spatial Structure } & \multicolumn{4}{|c|}{ Environmental Quality } & \multicolumn{6}{|c|}{ Social Development } \\
\hline & e11 & e12 & e13 & e14 & e21 & e22 & e23 & e24 & e25 & e31 & e32 & e33 & e34 & e41 & e42 & e43 & e44 & e51 & e52 & e53 & e54 & e55 & e56 \\
\hline 2006 & 0.0000 & 0000 & 0000 & 000 & 0000 & 1238 & 5 & 5 & 000 & 463 & 117 & 0000 & 000 & 000 & 0000 & 0000 & 0000 & 0.0000 & 0.0000 & 0.0157 & 0.0000 & 0000 & 0000 \\
\hline 2007 & & & & & & & & & & & & & & & & & & & & & & & \\
\hline & & & & & & & & & & & & & & & & & & & & & & & \\
\hline 2005 & & 0. & & & 1 & & & & & & & & & 4 & & & & 0.3 & 0.1 & & & & 12 \\
\hline & & & & & & & & & & & & & & & & & & & & & & & \\
\hline 2011 & 0. & 0. & 7 & & 9 & 6 & & & & & 8 & 0.3 & & 99 & 56 & 0.7869 & & 0.5 & 0.3296 & 69 & 13 & 0.7 & 0.6792 \\
\hline & & & & & & & & & & & & & & & & & & & & & & & 0.8239 \\
\hline 2013 & 0. & 0 & 6 & & & & & & & 31 & $z$ & & & 0.8 & 0.8 & 0.9 & & 0.6 & 0.5 & 66 & 99 & 00 & 0.9119 \\
\hline 20 & & & & & & & & & & & & & & & & & & & & & & & \\
\hline 2015 & 1.0000 & 1.0000 & 1.0000 & 1.0000 & 1.0000 & 1.0000 & 1.0000 & 1.0000 & 1.0000 & 1.0000 & 0.7512 & 1.0000 & 1.0000 & 0.8909 & 1.0000 & 1.0000 & 1.0000 & 1.0000 & 1.0000 & 1.0000 & 1.0000 & 0.8668 & 0.9560 \\
\hline
\end{tabular}


Table 5. Order degree of all subsystems and synergy degree of the composite system.

\begin{tabular}{cccccccc}
\hline Year & $u_{1}\left(e_{1}\right)$ & $u_{2}\left(e_{2}\right)$ & $u_{3}\left(e_{3}\right)$ & $u_{4}\left(e_{4}\right)$ & $u_{5}\left(e_{5}\right)$ & $S D$ & $s d$ \\
\hline 2006 & 0 & 0.035 & 0.271 & 0 & 0.002 & & \\
2007 & 0.124 & 0.094 & 0.148 & 0.130 & 0.061 & -0.0929 & -0.0929 \\
2008 & 0.173 & 0.104 & 0.039 & 0.245 & 0.137 & -0.1557 & -0.0542 \\
2009 & 0.158 & 0.189 & 0.558 & 0.350 & 0.446 & 0.2553 & -0.1165 \\
2010 & 0.267 & 0.227 & 0.459 & 0.435 & 0.515 & 0.2928 & -0.0752 \\
2011 & 0.364 & 0.382 & 0.577 & 0.460 & 0.643 & 0.4087 & 0.0893 \\
2012 & 0.688 & 0.543 & 0.707 & 0.548 & 0.741 & 0.5729 & 0.1424 \\
2013 & 0.763 & 0.679 & 0.751 & 0.806 & 0.840 & 0.6925 & 0.1028 \\
2014 & 0.947 & 0.832 & 0.828 & 0.902 & 0.887 & 0.8038 & 0.0996 \\
2015 & 1 & 1 & 0.894 & 0.983 & 0.971 & 0.8945 & 0.0832 \\
\hline
\end{tabular}




\section{Results Analysis}

In order to more intuitively reflect the cooperative evolutionary trend of each subsystem and the overall system, the development trend is drawn from the data in Tables 4 and 5, as shown in Figure 4 .

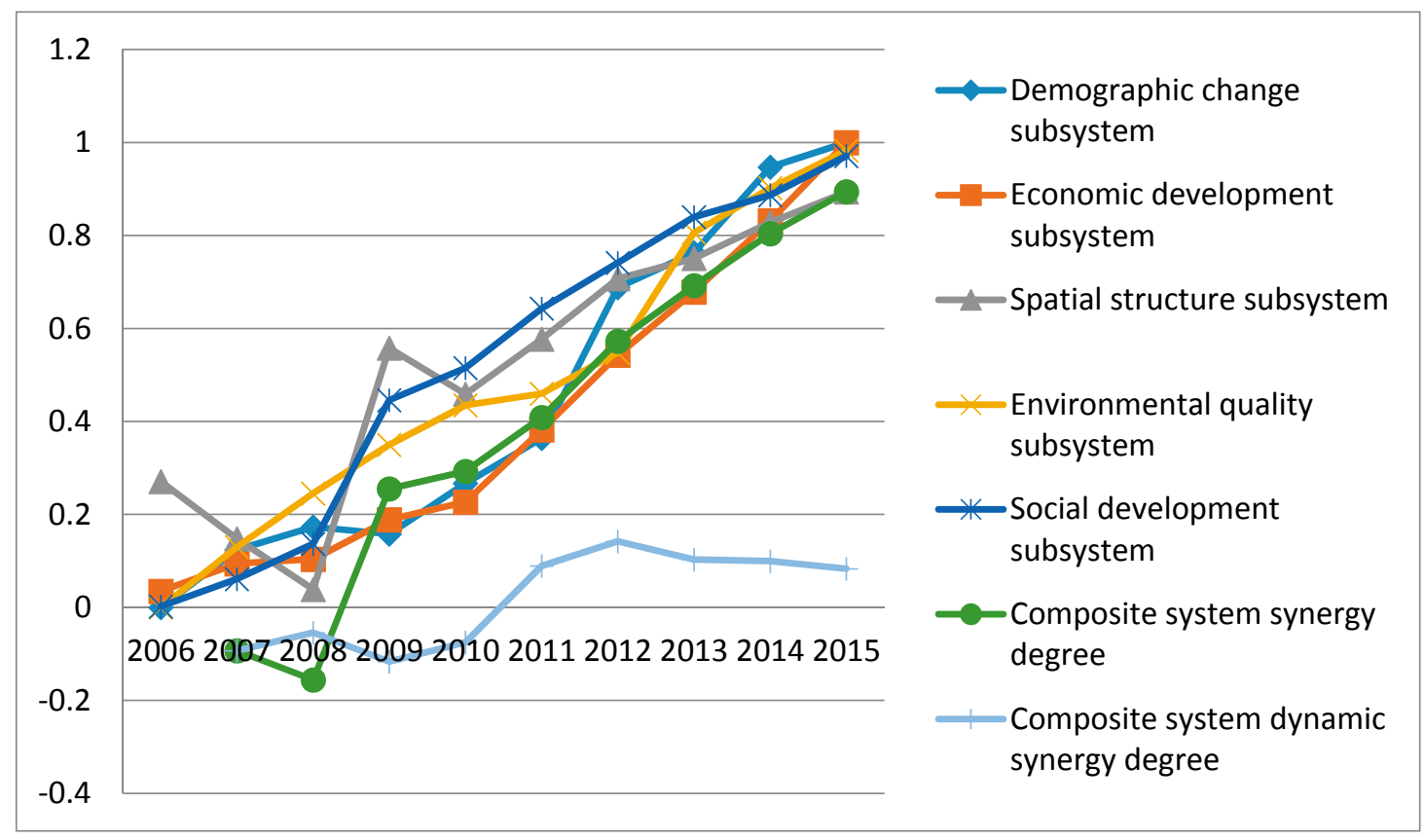

Figure 4. Development trend of the order degree of the sustainable urbanization subsystems and synergy degree of the composite system in Henan.

\subsection{Analysis of the Subsystem Order Degree of the Sustainable Urbanization}

As can be seen from Table 5 and Figure 4, in 2006-2010, on the whole, the order degrees of the subsystems of sustainable urbanization fluctuated but steadily increased from 2011 to 2015 . From 2006 to 2015, the order degrees of all the subsystems of sustainable urbanization increased to varying degrees, indicating that the five subsystems have the ability for self-organization. Over this period, the social development subsystem and the spatial structure subsystem order degrees were relatively higher than the others, and the order degree of the economic development subsystem was the lowest.

(1) The demographic change subsystem order degree was increasing from 2006 to 2015, with the order degree improvement particularly evident after 2011. Since the 11th Five-Year Plan, Henan province has attached great importance to an orderly population flow and a reasonable population distribution. In the past ten years, the urban population has increased by 19.31 million, and the urban unemployment rate has decreased to $3 \%$. Further, the secondary and tertiary industry has increased urban employment opportunities, thereby contributing to the development of population urbanization. These changes appeared to suggest that the demographic change subsystem has been developing gradually into an orderly state. However, it is worth noting that the phenomenon of disequilibrium exists in Henan population urbanization.

(2) The improvement of the order degree of the economic development subsystem was the same as that of the demographic change subsystem, but the fluctuations were small. As a large agricultural province, Henan's economy has been steadily developing during urbanization. The labor force has shifted from primary industry to secondary industry, and with the further increases in the per capita GDP income level, there has been a gradual shift to the tertiary industry. At the end of 2015, the proportion of the tertiary industry increased to $40.2 \%$, leading to an increase in the order degree of the economic development subsystem. Additionally, the progress of order 
degree of sustainable urbanization in Henan has also been driven by the increase in the income of residents and the increased investment in fixed assets by the government over the past ten years. In addition, in 2011, the construction of the Central Plains Economic Zone has been brought into the national 12th Five-Year Plan, which has officially risen to the national strategy, and the pace of building in Henan's Central Plains Economic Zone has been greatly accelerated since 2011. As shown in Figure 4, from 2011, the trend curve became more inclined; however, compared with the other subsystems, the economic development in Henan province is not sufficient, which is also in line with Henan's reality.

(3) The order degree of the spatial structure subsystem first decreased from 0.271 in 2006 to the minimum value in 2008, and then increased. There were two reasons for this. First, the urban population growth and urban area expansion were not coordinated. Second, since Henan province had a large population output, the Beijing Olympic Games and the economic depression in 2008 caused limited population output, resulting in an increase in population density and a decline in the urban resident per capita road area. As the population density and the urban resident per capita road area weights were larger in the spatial structure subsystem, any changes would have a significant influence on the spatial structure subsystem order degree.

(4) The order degree of the environmental quality subsystem continuously improved. Among them, the harmless treatment rate of municipal solid waste had risen significantly from $46.3 \%$ in 2006 to $96 \%$ in 2015-a significant improvement. The urban sewage treatment rate increased from $66.32 \%$ in 2006 to $93.58 \%$ in 2015, and environmental governance investment increased by almost four times over the past years, all indicating that some achievements have been made in the construction of ecological civilization, and the quality of the urban environment has been increasingly improved in Henan.

(5) The order degree of the social development subsystem was increasing year on year and was somewhat higher than that the other subsystems. Due to the varying improvement degrees in each of the order parameter indices from 2006 to 2015, the system has moved in an orderly direction, as exemplified in the increase of $18.8 \%$ in the gas popularization rate, the threefold increase in the medical insurance numbers in cities and towns, and the increase to 47,766 in total amount of patent authorization, all of which demonstrated that urbanization was developing well. Compared with the other subsystems, and especially from 2009-2015, the social subsystem had the highest order degree, indicating that more attention had been paid to it.

\subsection{Analysis of Synergy Degree of the Sustainable Urbanization Composite System}

From the above analysis, it can be known that the premise for a positive synergy degree value of the sustainable urbanization composite system is that the order degrees of all subsystems at time $t_{m}$ should be greater than its order degree at the initial time $t_{0}$, suggesting that the composite system is in the state of synergistic evolution. As can be seen in Figure 4, the synergy degree of the composite system was negative before 2009, which resulted from the disorderly development of the spatial structure subsystem. From 2009 to 2015, the value of the synergy degree of the sustainable urbanization composite system was positive and increased steadily, showing that the synergy system of sustainable urbanization developed to an ordered state as a whole. From a dynamic point of view (with the base period being one year ahead of each year), the order degrees of all of the subsystems every year were larger than the previous year after 2010 (Table 5), leading to the positive value of synergy degree from 2011 to 2015 (Figure 4). However, the synergy degree is negative before 2011, indicating that the development of each subsystem is not all orderly than that of the previous year. 
Taking five years as a time period, the synergy degree of the composite system from 2006 to 2011 is $S D_{0}=0.4087$ from Table 5. The synergy degree from 2010 to 2015 can be calculated using Equations (5) and (6):

$$
S D_{1}=\theta\left\{\left|\prod_{i=1}^{k}\left[u_{i}{ }^{2015}\left(e_{i}\right)-u_{i}{ }^{2010}\left(e_{i}\right)\right]\right|\right\}^{1 / k}=\theta\left\{\left|\prod_{i=1}^{5}\left[u_{i}{ }^{2015}\left(e_{i}\right)-u_{i}{ }^{2010}\left(e_{i}\right)\right]\right|\right\}^{1 / 5}=0.5771
$$

From a comparison of $S D_{0}$ and $S D_{1}$, the improvement of the synergy degrees of the sustainable urbanization composite system from 2006 to 2011 and from 2010 to 2015 can be observed. $S D_{1}>S D_{0}>0$ suggests that the composite system was in a synergistic development state in these two stages, but the progress of the synergy degrees from 2010 to 2015 is greater than that from 2006 to 2011. The main reason was that in 2011, the beginning of the 12th Five-Year Plan, Henan first introduced a series of policies focused on the scientific coordination development road of the new urbanization, and explored out a sustainable urbanization road. Consequently, it can be seen from Figure 4 that the order degree improvement trend of all of the subsystems is more obvious from 2011.

The synergistic evolution of a composite system is determined by the synergistic mechanisms between the demographic, economic, spatial, ecological, and social subsystems. By calculation, the average synergy degree of the composite system was 0.2753 from 2006 to 2015, which showed that although the trend was rising, the synergy degree level of the sustainable urbanization system in Henan province was still not high. From Figure 4, it was found that the economic development subsystem is the "short board" and determined the lower synergy degree of composite subsystem to a certain extent.

\section{Conclusions}

From an analysis of the structure and functions of a sustainable urbanization system, based on the "China Statistical Yearbook" and the "Henan Statistical Yearbook" from 2007 to 2016 [41,42], this paper developed a SUSS that had five key subsystems; demographic change, economic development, spatial structure, environmental quality and social development. Combined with the CRITIC weighted method, the synergetic theory was introduced and a synergy degree model was used to study the order degree of all subsystems and the synergetic degree of the composite system. From this study, the following conclusions were drawn:

(1) To measure the sustainable urbanization synergistic effects, this paper developed a SUSS with selected subsystem order parameters to examine the concept of sustainable urban development, the effectiveness and feasibility of which was verified in a pilot case study. The CRITIC method was used to determine the order parameters weights to avoid subjective preferences, which made the results more objective and representative.

(2) Sustainable urbanization is a complex system affected by many factors and its development is a dynamic evolution process based on time series. Through the application of a synergy theory, the order degree value changes of the five subsystems and the synergy degree value changes of the composite system can be analyzed so as to scientifically reflect the systematic characteristics and development status in the process of urbanization.

(3) Through the analysis of the order degree change of each subsystem and the synergy degree change of the composite system in Henan province from 2006 to 2015, it was found that although synergistic effects were developing into an ordered state, there was still much room for improvement, especially in terms of the economic development subsystem, which needs to be further reinforced.

Sustainable urbanization is a multi-dimensional, multi-structured, complex system that is affected by many factors. Although the order parameters in this paper were selected from multiple perspectives, there are still certain limitations. The synergy system does not contain all the elements that influence 
the sustainable urbanization synergy degree and the threshold of indicators is not considered in this paper. In addition, factors that affect the synergy degree vary over time, for study convenience this paper carried out a static independent analysis of subsystem order parameters, without considering the internal logical relationships between the order parameters and the effect of order parameter indices changes on measurement results. Therefore, further explorations on the order parameter index system and dynamic research will be the focus of the future research work.

Acknowledgments: This research was funded by the Foundation of Academic Leader Training in Sichuan Province ([2015]100-6).

Author Contributions: The study was designed by Leilei Jiao in collaboration with all co-authors. Data was collected by Fumin Deng. The first and final drafts were written by Leilei Jiao. The defects of draft were critiqued by Leilei Jiao and Xuedong Liang. The results were analyzed by Fumin Deng and Xuedong Liang. The research and key elements of models were reviewed by Fumin Deng. The writing work of corresponding parts and the major revisions of this paper were completed by Leilei Jiao.

Conflicts of Interest: The authors declare no conflict of interest.

\section{References}

1. Kumar, M.P.; Reddy, S. Analysis of Land Use/Land Cover Changes Using Remote Sensing Data and GIS at an Urban Area, Tirupati, India. Sci. World J. 2013, 2013, 268623. [CrossRef]

2. Shen, L.Y.; Zhou, J.Y. Examining the effectiveness of indicators for guiding sustainable urbanization in China. Habitat Int. 2014, 44, 111-120. [CrossRef]

3. Lu, S.S.; Guan, X.L.; He, C.; Zhang, J.L. Spatio-Temporal Patterns and Policy Implications of Urban Land Expansion in Metropolitan Areas: A Case Study of Wuhan Urban Agglomeration, Central China. Sustainability 2014, 6, 4723-4748. [CrossRef]

4. Wang, S.J.; Fang, C.L.; Guan, X.L.; Pang, B.; Ma, H. Urbanization, energy consumption, and carbon dioxide emissions in China: A panel data analysis of China's provinces. Appl. Energy 2014, 136, 738-749. [CrossRef]

5. Liu, S.W.; Zhang, P.Y.; Jiang, X.L.; Lo, K. Measuring sustainable urbanization in China: A case study of the coastal Liaoning area. Sustain. Sci. 2013, 8, 585-594. [CrossRef]

6. Liang, X.D.; Zhang, W.W.; Chen, L.; Deng, F.M. Sustainable Urban Development Capacity Measure-A Case Study in Jiangsu Province, China. Sustainability 2016, 8, 270. [CrossRef]

7. Yu, A.T.W.; Wu, Y.; Zheng, B.; Zhang, X.; Shen, L. Identifying risk factors of urban-rural conflict in urbanization: A case of China. Habitat Int. 2014, 44, 177-185. [CrossRef]

8. Tosics, I. The Chinese urban development dilemma: heritage and green areas as victims of rapid urbanization. Mazowieckie Biuro Planowania Regionalnego W Warszawie 2012, 9, 87-100.

9. Yigitcanlar, T. Smart cities: An effective urban development and management model? Aust. Plan. 2015, 52, 27-34. [CrossRef]

10. Zhou, J.Y.; Shen, L.Y.; Song, X.N.; Zhang, X. Selection and modeling sustainable urbanization indicators: A responsibility-based method. Ecol. Indic. 2015, 56, 87-95. [CrossRef]

11. Sobczyk, W. Sustainable Development of Middle East Region. Problemy Ekorozw. 2015, 10, 51-62.

12. Dassen, T.; Kunseler, E.; Van Kessenich, L.M. The Sustainable City: An Analytical-Deliberative Approach to Assess Policy in the Context of Sustainable Urban Development. Sustain. Dev. 2013, 21, 193-205. [CrossRef]

13. Chen, Z.L.; Su, L.C.; Zhang, C. Research on the Synergy Degree of Aboveground and Underground Space along Urban Rail Transit from the Perspective of Urban Sustainable Development. Sustainability 2016, 8, 934. [CrossRef]

14. Liu, Y.Q.; Xu, J.P.; Luo, H.W. An Integrated Approach to Modelling the Economy-Society-Ecology System in Urbanization Process. Sustainability 2014, 6, 1946-1972. [CrossRef]

15. Srinivasan, V.; Seto, K.C.; Emerson, R.; Gorelick, S.M. The impact of urbanization on water vulnerability: A coupled; human-environment system approach for Chennai, India. Glob. Environ. Chang. 2013, 23, 229-239. [CrossRef]

16. Shen, L.; Cheng, S.K.; Gunson, A.J.; Wan, H. Urbanization, sustainability and the utilization of energy and mineral resources in China. Cities 2005, 22, 287-302. [CrossRef]

17. Li, S.S.; Ma, Y. Urbanization, Economic Development and Environmental Change. Sustainability 2014, 6, 5143-5161. [CrossRef] 
18. Zhang, H.Y.; Uwasu, M.; Hara, K.; Yabar, M. Sustainable Urban Development and Land Use Change-A Case Study of the Yangtze River Delta in China. Sustainability 2011, 3, 1074-1089. [CrossRef]

19. Dewan, A.M.; Yamaguchi, Y. Effect of land cover changes on flooding: Example from Greater Dhaka of Bangladesh. Int. J. Geoinform. 2008, 4, 11-20.

20. Shen, L.Y.; Peng, Y.; Zhang, X.L.; Wu, Y.Z. An alternative model for evaluating sustainable urbanization. Cities 2012, 29, 32-39. [CrossRef]

21. Harris, N. Wastes, the environment and the international economy. Cities 1992, 9, 177-185. [CrossRef]

22. Marcotullio, P.J. Asian urban sustainability in the era of globalization. Habitat Int. 2001, 25, 577-598. [CrossRef]

23. Jaeger, J.A.G.; Bertiller, R.; Schwick, C.; Kienast, F. Suitability criteria for measures of urban sprawl. Ecol. Indic. 2010, 10, 397-406. [CrossRef]

24. Huang, L.; Yan, L.J.; Wu, J.G. Assessing urban sustainability of Chinese megacities: 35 years after the economic reform and open-door policy. Landsc. Urban Plan. 2016, 145, 57-70. [CrossRef]

25. Shen, L.Y.; Ochoa, J.; Shah, M.N.; Zhang, X.L. The application of urban sustainability indicators-A comparison between various practices. Habitat Int. 2011, 35, 17-29. [CrossRef]

26. Mori, K.; Yamashita, T. Methodological framework of sustainability assessment in City Sustainability Index (CSI): A concept of constraint and maximization indicators. Habitat Int. 2015, 45, 10-14. [CrossRef]

27. Zhang, X.L. Sustainable urbanization: a bi-dimensional matrix model. J. Clean. Prod. 2016, 134, 425-433. [CrossRef]

28. Li, Y.F.; Li, Y.; Zhou, Y.; Shi, Y.L. Investigation of a coupling model of coordination between urbanization and the environment. J. Environ. Manag. 2012, 98, 127. [CrossRef] [PubMed]

29. Tavernia, B.G.; Reed, J.M. Spatial extent and habitat context influence the nature and strength of relationships between urbanization measures. Landsc. Urban Plan. 2009, 92, 47-52. [CrossRef]

30. Shen, L.Y.; Zhou, J.Y.; Skitmore, M.; Xia, B. Application of a hybrid Entropy-McKinsey Matrix method in evaluating sustainable urbanization: A China case study. Cities 2015, 42, 186-194. [CrossRef]

31. Qiao, B.; Fang, C.G. The dynamic coupling model and its application of urbanization and eco-environment in Hexi Corridor. J. Geogr. Sci. 2005, 15, 491-499. [CrossRef]

32. Buhaug, H.; Urdal, H. An urbanization bomb? Population growth and social disorder in cities. Glob. Environ. Chang. 2013, 23, 1-10. [CrossRef]

33. Sato, Y.; Zenou, Y. How Urbanization Affect Employment and Social Interactions. Eur. Econ. Rev. 2015, 75, 131-155. [CrossRef]

34. Haken, H. Synergetics: An Overview. Rep. Prog. Phys. 1989, 52, 515-553. [CrossRef]

35. Haken, H. Basic concepts of synergetics. Appl. Phys. A Solids Surf. 1993, 57, 111-115. [CrossRef]

36. Heuvel, F.V.D.; Donselaar, K.V.; Langen, P.D.; Fransoo, J. Co-Location Synergies: Specialised Versus Diverse Logistics Concentration Areas. Tijdschrift Voor Economische En Sociale Geografie 2016, 107, 331-346. [CrossRef]

37. Buultjens, J.; Gale, D.; White, N.E. Synergies between Australian indigenous tourism and ecotourism: Possibilities and problems for future development. J. Sustain. Tour. 2010, 18, 497-513. [CrossRef]

38. Diakoulaki, D.; Mavrotas, G.; Papayannakis, L. Determining objective weights in multiple criteria problems: The critic method. Comput. Oper. Res. 1995, 22, 763-770. [CrossRef]

39. Kazan, H.; Ozdemir, O. Financial performance assessment of large scale conglomerates via TOPSIS and CRITIC methods. Int. J. Manag. Sustain. 2014, 3, 203-224.

40. He, L.X.; Chen, B.X. The present situation, causes and Countermeasures of urbanization in Henan province. China's Urban Econ. 2010, 9, 259-261.

41. People's Republic of China National Bureau of statistics. China Statistical Yearbook; China Statistics Press: Beijing, China, 2007-2016. Available online: http:/ / www.stats.gov.cn/tjsj/ndsj/ (accessed on 11 October 2017).

42. Henan Bureau of Statistics. Henan Statistical Yearbook; China Statistics Press: Beijing, China, 2007-2016. Available online: http://www.ha.stats.gov.cn/sitesources/hntj/page_pc/tjfw/tjcbw/tjnj/list1.html (accessed on 11 October 2017).

(c) 2017 by the authors. Licensee MDPI, Basel, Switzerland. This article is an open access article distributed under the terms and conditions of the Creative Commons Attribution (CC BY) license (http://creativecommons.org/licenses/by/4.0/). 